\title{
Patient Education and Self-Management in the Rheumatic Diseases: A Self-Efficacy Approach
}

\author{
Erik Taal, Johannes J. Rasker, and Oene Wiegman
}

As stated in the standards for arthritis patient education recently developed by a task force of the $\mathrm{Na}$ tional Arthritis Advisory Board in the United States $(1,2)$, patient education can improve the lives of patients with rheumatic diseases. Patients need a formal body of knowledge and skills in order to manage the disease on a day-to-day basis. These standards give the following definition of patient education:

Patient education is planned, organized learning experiences designed to facilitate voluntary adoption of behaviors or beliefs conducive to health. It is a set of planned educational activities that are separate from clinical patient care. The activities of a patient education program must be designed to attain goals the patient has participated in formulating. The primary focus of these activities includes acquisition of information, skills, beliefs and attitudes which impact on health status, quality of life, and possibly health care utilization.

This definition, compared to more traditional definitions, emphasizes that patient education should lead not only to changes in knowledge, but also to changes in behavior and in health status. It stresses the importance of assessing the needs of the patients and of tailoring patient education to those needs. Indeed, a thorough analysis of patients' health problems, of the be-

Supported by a grant from the Ministry of Health, Welfare, and Sports of The Netherlands.

Erik Taal, $\mathrm{PhD}$, Social Psychologist, and Oene Wiegman, PhD, Psychologist, Professor, Department of Psychology, University of Twente; and Johannes J. Rasker, MD, $\mathrm{PhD}$, Professor, Department of Psychology, University of Twente, and Rheumatologist, Department of Rheumatology, Medisch Spectrum Twente, Enschede, The Netherlands.

Address correspondence to Erik Taal, $\mathrm{PhD}$, Department of Psychology, University of Twente, P. O. Box 217, 7500 AE Enschede, The Netherlands.

Submitted for publication February 27, 1995; accepted in revised form January 26, 1996.

(C) 1996 by the American College of Rheumatology. haviors involved with the problem, and of the determinants of the behavior are needed $(3,4)$.

A wide range of behaviors can be important in the management of rheumatic diseases. Among the behaviors that are thought to influence physical and psychosocial health status (such as pain, disability, depression) are adherence to medication regimens, physical exercise, relaxation exercises, joint protection measures, rest, pain coping strategies, and problem-solving (5-9). Studies evaluating the effects of educational interventions should measure not only changes in knowledge but also changes in behavior and in physical and psychosocial health.

In various reviews of arthritis patient education programs, it has been concluded that educational interventions can be effective in changing knowledge, behaviors, and physical and psychosocial health status. Patient education programs have consistently been shown to increase patients' knowledge $(5,8)$. Effects on behavior and health status are less clear. This is partly because so often, only knowledge has been assessed, especially in older studies. In recent years, there has been increasing attention to behavioral and health status effects. In their 1987 review, Lorig et al (8) found that $12 \%$ of the studies they evaluated examined only knowledge, while Hirano and co-workers' review of studies published between 1987 and 1991 (6) showed no studies that measured only knowledge. They found that since 1987, there was also an increase in the number of studies measuring knowledge, behavior, and psychosocial and physical health status (6). In evaluating the effects of patient education on health status, one must consider the fact that patient education is provided in addition to standard medical care (8). Many evaluation studies use control or comparison groups, but usually, these comparison groups continue to receive standard care (10). So, the effects of patient ed- 
ucation are always supplementary to the benefits of medication or other standard medical care.

In patient education there has always been the implicit assumption that changes in behavior lead to changes in health status. Several studies have indeed shown patient education to be effective in changing behavior and changing health status, but the relationships between these changes are not consistent $(5,8)$. Recently, Hirano et al (6) concluded that the mechanisms that make arthritis patient education studies effective or the type of intervention or combination of interventions that are effective are still not known. So, future studies should investigate relevant factors that can facilitate or mediate beneficial effects, thereby clarifying the causal relationship between intervention and outcome $(5-8,11)$. It is important that research into the effects of patient education is based on theoretical models of behavior change $(5,10)$. The assumptions of these models should be empirically tested.

\section{Self-management}

Patients with chronic rheumatic diseases have an important role in the management of their disease. As stated in the above-quoted patient education standards, patients need skills for managing their disease on a day-to-day basis $(1,2)$. Self-management means that the individual assumes preventive or therapeutic health care activities, often in collaboration with health care professionals (12). It means having, or being able to obtain, the skills and resources necessary to best accommodate to the disease and its consequences $(12,13)$. An important aspect of self-management is the collaborative relationship between patients and health care professionals. The patient does not stand alone in the daily management of the disease. The health care professionals are there to teach and to provide expert knowledge and needed skills (13).

In rheumatoid arthritis (RA), adequate self-management is extremely important. This disease is chronic and disabling, and is characterized by an unpredictable course, with periods of exacerbation and remission of disease activity $(14,15)$. Since RA cannot be cured, the goals of treatment and management are the relief of pain, the prevention of joint destruction, and the preservation or improvement of the patient's functioning. Treatment is usually a combination of rest, exercise, and medication (16). This regimen must constantly be adjusted to the changing disease activity. Therefore, the patient has to learn to adjust rest, exercise, and medication to disease activity that sometimes varies daily. Patient education can help patients make informed decisions about adjustment in their treatment regimen and in attaining the necessary self-management skills for dealing with the consequences of their disease. This means that patient education aimed at improving selfmanagement should teach patients more than adherence to a treatment regimen of medication and physical exercises. Other important skills are the practice of relaxation exercises, joint protection measures, and strategies for coping with pain and stress. Patient education should also include the teaching of more general skills, such as decision-making, problem-solving, and communication.

\section{Social learning theory and self-management}

The basic assumption of Bandura's social learning theory $(17,18)$ is the concept of reciprocal determinism. According to reciprocal determinism, human functioning involves a continuous interaction between behavioral, cognitive, and other personal factors and environmental influences.

Applying this model to health and illness means that health and illness can be viewed as a result of the interaction between biological, psychological, behavioral, and environmental factors. This model finds its analogy in the biopsychosocial model of health and illness that was developed by Engel in 1977 (19) as a reaction to the traditional biomedical model $(18,20)$. This view implies that biological, psychological, and social variables interact to determine the course of health and illness, while the traditional biomedical model assumes disease to be fully accounted for by biological (somatic) variables (19).

According to social learning theory, much of an individual's behavior is motivated and regulated by internal standards and self-evaluative reactions to the person's own actions (17). Outcome expectations and self-efficacy expectations are especially important cognitive-mediating mechanisms in changing behavior. Outcome expectation refers to a person's estimate that a recommended behavior will have a beneficial effect. Self-efficacy expectation refers to beliefs in one's capabilities to successfully execute the behavior required to produce a certain desired outcome. Outcome and self-efficacy expectations are differentiated because people can believe that certain actions will produce a positive outcome, but if they have serious doubts about whether they can perform the necessary activities themselves, such information does not affect their behavior.

Self-efficacy expectations regulate human functioning in diverse ways. Self-efficacy expectations affect behavioral choices and the amount of effort people will make, and how long they will persevere in the face of difficulties. It influences whether their thought patterns take self-hindering or self-aiding forms, and affects the 
amount of stress they experience in coping with environmental demands $(17,21)$. People's perceptions of their coping self-efficacy have been shown to affect heart rate, blood pressure, and serum levels of catecholamines in threatening situations (22). Bandura states that perceived self-efficacy is a significant determinant of human functioning that operates partially independent of underlying skills (17). For example, in a study of patients with tension headaches, it was found that the benefits of biofeedback may stem more from increased self-efficacy beliefs about coping with pain than from the muscle exercises themselves. High perceived self-efficacy created by the false feedback that one is a skilled relaxer and can control pain predicted a reduction in tension headaches, while the actual amount of change in muscle activity achieved in treatment was unrelated to the incidence of subsequent headaches (20). In patients recovering from a heart attack, it was found that perceived self-efficacy regarding physical capability is a better predictor of resumption of an active lifestyle than cardiovascular capacity $(17,23)$.

Self-efficacy has been shown to be important in relation to human functioning in various areas, e.g., mental and physical health, human development, or coping with environmental hazards or burglary $(17,21,24-26)$.

Self-efficacy is an important determinant of selfmanagement behavior. Self-management involves a constant process of making behavioral choices and decisions. Self-efficacy expectations strongly influence these choices and decisions. These expectations also determine the amount of effort made, and the persistence of the effort, in performing self-management activities $(17,27)$. Interventions to enhance self-management behavior and health functioning should be aimed at strengthening self-efficacy expectations.

How can self-efficacy be influenced? According to Bandura (17) self-efficacy expectations are based on 4 major sources of information. These sources can be used by individuals other than the patient, e.g., educators, to help enhance the patient's self-efficacy.

Performance accomplishments are the most influential source of efficacy information because they are based on personal mastery experiences. Successful outcomes raise self-efficacy expectations. Repeated failures undermine feelings of self-efficacy. When learning new skills, it is important to break up tasks into smaller, more manageable tasks, so that there is a gradual increase in self-efficacy. Goals should be realistic and attainable in order to prevent self-efficacy expectations from becoming undermined by failure. In patient education programs, it is important to have patients start with what they are sure they can do (28). For example, an arthritis patient who is capable of walking 100 meters is encouraged to do this 4 times a week, and then to gradually increase the distance (28).

One of the best ways to foster mastery is to have patients set personal goals for a specific behavior, and to write these goals in the form of a contract with themselves (29). These goals should be realistic and attainable. It is very important to provide patients with feedback about their performance. The combination of goal setting (in contracts) and feedback has been shown to be particularly effective in strengthening self-efficacy and mastering skills $(17,30)$.

The second source of efficacy information is vicarious experience (modeling). Seeing or visualizing the success of people similar to oneself raises one's beliefs about one's own capabilities. Patients who are successful in coping with certain problems can act as models for other patients (modeling or observational learning). This works very well in group education, where the group members help each other solve problems $(28,29)$. When a problem is stated, the leader should ask the other group members if anyone ever had a similar problem or has any ideas about how to solve the problem. This strategy teaches group members that they really are experts and have useful knowledge to share. Furthermore, it shows them they do not always have to rely on professionals for advice, and may generate new solutions not thought of by health professionals.

Modeling is closely related to social comparison processes. According to Festinger (31), people need to have stable, accurate appraisals of themselves. When objective information for performance accomplishments is not available, then people will compare their performances with those of other people (17). Information about successful performances by persons similar to themselves will persuade observers that they too can succeed. Information about the performances of dissimilar persons does not necessarily affect self-efficacy appraisals. For example, the successes of models with superior abilities are viewed by observers as being beyond their reach (17).

Persuasive communication is a third mode of influence that can be used to strengthen self-efficacy (17). By giving people instructions, suggestions, and advice, they become convinced that they have the capability to attain goals. This method is used most in patient education. However, using the technique to raise unrealistic self-efficacy expectations invites failures that will undermine expectations of self-efficacy. Persuasive communication is most effective when used in combination with other methods. Health educators can use persuasion to stimulate patients to gradually set their goals higher. In a group, patients can motivate 
and stimulate each other to start doing new activities. Patients not only act as models for other patients, but can also persuade and influence them.

People also rely on information from their physiological state. They interpret arousal and tension as signs of vulnerability to dysfunction (17). People often interpret physiological signals (pain, fatigue) as indicators of personal inefficacy in managing or coping with their disease. A fourth way to influence self-efficacy, then, is to change people's physiological reactions and their interpretation of their own physiological state (21). For example, patients often confuse the normal effects of exercise (muscle pain or fatigue) with symptoms of their arthritis. Patients have to learn to distinguish the pain of their arthritis from the typical muscle pain that follows exercise.

\section{Self-efficacy and rheumatoid arthritis}

In relation to RA, self-efficacy expectations seem to be of major importance. The unpredictable course and varying disease activity of RA may cause patients to view their disease as uncontrollable, leading to lower self-efficacy expectations about the "self-management" of the consequences of the disease (32). The feeling that they cannot control their disease may cause patients to experience anxiety and depression. This, in turn, can lead to increased perceptions of pain and reduced efforts to cope with the consequences of the disease or to engage in daily activities. As a result, health status will further deteriorate. Educational interventions aimed at strengthening self-efficacy expectations about managing pain and other physical or psychosocial consequences of the disease may lead to better self-management and, eventually, better health status.

Studies have shown that there are associations between self-efficacy expectations and health status in arthritis patients, and that changes in self-efficacy are related to changes in health status (Table 1). In arthritis patients, significant relationships were found between initial self-efficacy and levels of pain and disability 4 weeks later (33). Buescher et al (34) studied the relationships between self-efficacy beliefs and pain behaviors such as limps, facial grimaces, and guarded movements that are exhibited by RA patients. Higher selfefficacy was found to be related to fewer pain behaviors. The Arthritis Self-Management Program developed by Lorig et al (35) has been shown to result in increased knowledge, more consistent performance of health practices, and reductions in pain. However, associations between changes in behavior (physical exercise, relaxation, walking) and changes in health status were weak (36). Interviews with participants revealed that those who showed improved health status attributed their benefits to an increased sense of personal control over the symptoms of the disease. This indicated that patient education may work by enhancing feelings of self-efficacy. O'Leary et al (37) showed that strengthening of self-efficacy expectations in RA patients through a cognitive-behavioral intervention based on the Arthritis Self-Management Program was related to a reduction of pain, disability, and joint impairment and an increase in coping. The patients with higher perceived self-efficacy were also the patients who were less depressed and less stressed.

In a cross-sectional study of 86 RA patients, we found significant correlations between patients' expectations of their self-efficacy in coping with the consequences of their arthritis and their physical and psychological health status (38). Furthermore, the amount of problems RA patients had in adhering to health recommendations was not significantly correlated with functional disability, pain, or other aspects of their health status. But, we did find significant negative correlations between the amount of adherence problems and patients' self-efficacy expectations about coping with the consequences of arthritis.

To further study the role of self-efficacy in improving health status, Lorig et al (39) developed an instrument to measure the perceived self-efficacy of people with arthritis. They found significant associations between self-efficacy and both present and future (4 months later) health status (pain, depression, functional disability). Furthermore, changes in self-efficacy were related to changes in health status. To find out if increased self-efficacy improved health status, Lorig and colleagues developed 3 new versions of the Arthritis Self-Management Program, emphasizing physical exercise, cognitive pain management techniques, or both $(29,40)$. In all 3 versions, self-efficacy-enhancing strategies based on skills mastery, modeling, reinterpreting symptoms, and persuasion were used. Participants in all 3 courses demonstrated significant improvements in health status (pain, depression, disability) and selfefficacy. Changes in pain and self-efficacy from baseline to 4 months were significantly different between all 3 course groups and the controls. However, no significant differences between the 3 course groups were found. Thus, efficacy-enhancing arthritis patient education improved health status independently of the behaviors taught. Based on these findings, a new revised arthritis self-management course has been designed specifically to enhance self-efficacy. A study with $\mathbf{9 7}$ arthritis patients showed that the revised course produced greater increases in health status than did the original course (29).

In The Netherlands, we have developed a group ed- 
Table 1. Summary of results of studies of self-efficacy and arthritis*

\begin{tabular}{|c|c|c|}
\hline $\begin{array}{c}\text { Author (ref.), } \\
\text { year }\end{array}$ & Study sample & Method \\
\hline $\begin{array}{l}\text { Shoor and Holman } \\
\text { (33), } 1984\end{array}$ & $\begin{array}{l}\text { Sample 1: } \mathrm{n}=84 \\
\begin{array}{l}58 \% \text { OA, } 12 \% \mathrm{RA} \\
\text { Sample } 2: \mathrm{n}=166 \\
32 \% \text { OA, } 46 \% \text { RA }\end{array}\end{array}$ & Longitudinal, 4-week interval \\
\hline $\begin{array}{l}\text { Buescher et al (34), } \\
1991\end{array}$ & $72 \mathrm{RA}$ patients & Cross-sectional \\
\hline $\begin{array}{l}\text { O'Leary et al (37), } \\
1988\end{array}$ & 30 female RA patients & $\begin{array}{l}\text { Cognitive-behavioral interven- } \\
\text { tion; experimental design with } \\
\text { control group and pre- and } \\
\text { post-tests }\end{array}$ \\
\hline
\end{tabular}

Taal et al (38), $1993 \quad$ 86 RA patients Cross-sectional

Lorig et al (39), 1989

Lorig and Gonzalez (29), 1992, Part A

Lorig and Gonzalez (29), 1992, Part B

Taal et al (9), 1993

\begin{abstract}
Sample 1: $\mathrm{n}=97$, $56 \%$ OA, $15 \%$ RA; Sample 2: $\mathrm{n}=144$, $58 \%$ OA, $22 \%$ RA
\end{abstract}

423 arthritis patients 97 arthritis patients 57 RA patients
Longitudinal, 4-month interval; self-management intervention; experimental design with control group and pre- and posttests

Experimental design with preand post-tests and control group, and 3 efficacy-enhancing interventions (exercise, pain management, and combined course)

One experimental group with preand post-tests; final efficacy-enhancing self-management course

Group self-management education; experimental design with control group and pre- and post-tests (after 6 weeks, 4 months, and 14 months]
Significant findings

Cross-sectional: PSE, FSE, and total SE negatively correlated with pain (VAS) and disability (HAQ). Longitudinal: negative correlations between initial FSE and future disability, and between initial total SE and future pain and disability.

PSE, FSE, and OSE related to pain behavior after controlling for age and disease severity (anatomic stage, joint count).

Treatment led to increases in PSE, FSE, and GSE, and decreases in pain (rating scale) and joint impairment (joint count). At post-treatment, there were correlations between PSE and pain, between FSE and disability (HAQ) and joint impairment, and between GSE and depression (ZDS), stress (PSS), and coping. In the treatment group, changes in PSE were correlated with changes in pain; changes in FSE with changes in disability and joint impairment; and changes in GSE with changes in coping.

GSE related to health status (pain, physical, and psychological status [Dutch AMS]). GSE related to amount of adherence problems after controlling for health status. Health status was not significantly related to adherence problems.

Baseline FSE, PSE, and OSE correlated with baseline and 4-month pain (VAS), disability (HAQ), and depression (BDI); 4-month FSE, PSE, and OSE correlated with 4-month pain, disability, and depression. In the treatment group, changes in PSE correlated with changes in pain, changes in FSE with changes in disability, and changes in OSE with changes in depression.

Improvements from baseline to 4 months in the 3 intervention groups in terms of pain (VAS), disability (HAQ), depression (BDI), PSE, FSE, and OSE. Greater changes in pain, PSE, and OSE for all 3 interventional groups compared to controls. No significant differences between the 3 intervention groups.

Greater changes in pain (VAS), disability (HAQ), and depression (BDI) than original self-management course (not compared statistically).

Greater improvements in the experimental group compared to the controls at 6 weeks in knowledge, FSE, outcome expectations, relaxation and physical exercise, self-management activities, and disability (M-HAQ), at 4 months in knowledge, physical exercise, joint tenderness (Ritchie articular index), and disability, and at 14 months in knowledge, FSE, and physical exercise.

${ }^{\star} \mathrm{OA}=$ osteoarthritis; $\mathrm{RA}=$ rheumatoid arthritis; PSE = self-efficacy (SE) expectations for managing pain; FSE = SE expectations about physical function; total $\mathrm{SE}=$ total score on PSE and FSE; VAS $=$ visual analog scale; HAQ = Health Assessment Questionnaire; OSE = SE expectations for controlling other arthritis symptoms; GSE = SE expectations for coping with the consequences of arthritis in general; ZDS = Zung Depression Scale; PSS = Perceived Stress Scale; Dutch AIMS = the Dutch version of the Arthritis Impact Measurement Scales; BDI = Beck Depression Inventory; M-HAQ $=$ modified HAQ. 
ucation program for RA patients, using the self-efficacy approach (9). The results of this program were promising. Evaluation showed beneficial short-term effects on knowledge, self-efficacy expectations about physical functioning, outcome expectations, performance of relaxation and physical exercises, self-management activities, functional disability, and joint tenderness. Although after 14 months, many of the effects had disappeared, we still found effects on knowledge, the practice of physical exercises, and self-efficacy expectations about physical functioning.

Most of the evidence presented here about the role of self-efficacy in arthritis is correlational in nature, so causal inferences cannot be made. However, some studies show that changes in self-efficacy are correlated with changes in health status in arthritis patients $(37,39)$. Correlations between changes in self-efficacy and health status have also been found in other diseases (21-24). The significant correlations between changes in self-efficacy and changes in health status in arthritis patients do not prove that changes in self-efficacy lead to changes in health status. It may be that improved health status affects self-efficacy, or there may be other factors that cause both to change (29). However, the effects of the Arthritis Self-Management Program on health status were greater when efficacyenhancing strategies were incorporated in the course, which indicates that health status is influenced by selfefficacy (29).

Further indications of the importance of self-efficacy come from cognitive-behavioral approaches to pain management (41). One of the assumptions underlying cognitive-behavioral treatment is that patients' beliefs influence their coping efforts. Because of the unpredictable nature of RA, patients may believe that their pain is uncontrollable. This may lead them to use maladaptive, passive styles of coping with their pain, such as restricting social activities or catastrophizing (42). In cognitive-behavioral therapy, patients are taught to reconceptualize their problems (e.g., pain) from being uncontrollable to being manageable. The treatment is designed to enhance patients' self-efficacy expectations about their abilities to exercise control over their pain and teach them to use more adaptive pain-management strategies, such as cognitive restructuring, attention diversion, relaxation exercises, imagery, and biofeedback $(41,43)$. Several studies have supported the short-term effectiveness of cognitive-behavioral pain management programs for RA patients (43). The results of successful programs imply improvement in the area of self-efficacy and the use of adaptive coping styles $(37,44)$. It would be worthwhile to integrate aspects of cognitive-behavioral therapy in educational programs based on the self-efficacy approach, as has been done by O'Leary et al (37). For RA patients who feel very helpless and engage in maladaptive coping, this might be a promising way to improve their self-efficacy in managing the consequences of their disease.

\section{Social influences}

The choice of activities that people undertake is greatly influenced not only by their self-efficacy expectations, but also by their social environments. Whether people's actions are socially impeded or supported depends, in part, on how efficacious others perceive them to be (17). For RA patients, who are often dependent to some extent on their spouses, partners, or close relatives for the fulfillment of daily tasks, developing adequate self-management behavior is a process that involves social interaction. The perceptions of the patient's spouse or other close relatives of the patient's capacities to cope with the consequences of the disease may be an important factor in that process (17).

In a study of men who were undergoing cardiac rehabilitation, the spouse's perception of the physical and cardiac capacities of the patient was found to affect exercise compliance and recovery $(17,45)$. Active participation of patients' spouses in an exercise program with treadmill activities increased the spouses' perceptions of their husbands' physical and cardiac efficacy, and had a positive effect on the patients' recovery. Spouses who only observed or were uninvolved in the treadmill activities did not change their doubts about their husbands' capacities $(17,45)$. This study showed that wives who had positive beliefs about their husbands' physical and cardiac capacities were more likely to encourage them to perform their exercises and resume an active lifestyle than were wives who doubted their husbands' capacities (17).

Several studies of arthritis patients have shown the health benefits of supportive relationships $(46,47)$. Social support has been found to correlate significantly with health status and the ability of patients to cope with the stressful consequences of arthritis. Some studies have taken both positive and negative aspects of social interactions in close relationships into account. Manne and Zautra (48) found that women with RA who were frequently criticized by their husbands engaged in more maladaptive coping behavior. However, support that was perceived as being positive led to more adaptive coping. In another study among RA patients, it was found that positive support from members of a close social network was related to less depression, while negative support was related to increased depression (49).

In an evaluation of the effects of a cognitive-behavioral program for the enhancement of pain management skills on pain, psychological status, and disease activity 
in patients with RA, Radojevic et al (50) considered the possible effects of involving a family member. Cognitive-behavioral therapy with active involvement of a family member proved to be more effective than cognitive-behavioral therapy without family support, discussion groups with family support, or a control group that did not participate in either cognitive-behavioral therapy or a discussion group. After the interventions, the patients who had received cognitive-behavioral therapy with family support achieved significantly greater reductions in joint swelling and numbers of swollen joints than did the patients in the other 3 groups.

As part of the study of the effects of our group selfmanagement education program for RA patients, we examined whether the participation of spouses in educational group sessions for RA patients led to additional beneficial effects (51). Data were collected from 27 RA patients who participated in our group self-management education program at baseline and after 6 weeks, 4 months, and 14 months. Spouses were invited to participate. The spouses of 10 patients participated in the group sessions. We found statistically significant beneficial effects of spouses' participation on perceived social support, self-efficacy regarding physical and endurance exercises, self-efficacy regarding self-management, self-efficacy about coping with pain, and practice of endurance exercises as well as self-management activities. However, our study population was small, and spouse participation was not experimentally manipulated. Further methodologically sound studies on this important topic are needed.

\section{Criteria for educational self-management programs}

Based on the standards of arthritis patient education and the self-efficacy approach, criteria can be delineated for the development and evaluation of educational self-management programs for arthritis patients. These criteria are partly based on criteria that have been developed in relation to self-management programs for children with asthma $(27,52,53)$.

1. A thorough problem analysis. Patient education should be tailored to the needs of the patients. Before developing an educational intervention, there should be a thorough analysis of the health problems that patients experience as well as the determinants of these problems. This can be done through a needs assessment survey among patients and/or by reviewing the scientific literature.

2. The use of a theoretical model. Educational interventions should be based on a theoretical model that clearly indicates the relationships between the meth- ods of influence that are used and the (behavioral) outcomes. We propose the use of educational methods based on the self-efficacy approach.

3. An attempt to influence knowledge, behavior, and health status. Patient education should lead not only to changes in knowledge, but also to changes in behavior (e.g., exercising, coping, problem-solving) and changes in health status (e.g., pain, disability, depression).

4. An attempt to teach effective self-management skills. Educational self-management programs should teach patients effective skills for the self-management of their arthritis. This means that these programs have to teach more than adherence to treatment. Many selfmanagement skills are derived from cognitive-behavioral therapy. Important skills are the practice of physical and relaxation exercises, problem-solving, decision-making, strategies for coping with pain and stress, and communication. The learning and use of new skills demands a lot of effort and takes much training time. It is not enough to provide patients with information about these skills. The skills themselves should be practiced during educational sessions, and patients should be encouraged to practice at home and practice materials can be supplied to them.

5. The use of effective methods of teaching self-management skills and strengthening self-efficacy appraisals. Often, only persuasive communication is used as an educational method. But, the transfer of knowledge alone does not necessarily lead to changes in behavior and self-efficacy. The most effective methods are those based on performance accomplishments (for example, goal-setting in contracts in combination with feedback) and vicarious experience (for example, having patients act as models for other patients).

6. The involvement of people from the patient's social environment (spouse, close relatives). The performance of adequate self-management behavior depends in part on the support patients receive from their spouses or other close relatives. Whether a patient's actions are supported and encouraged depends on how efficacious others perceive him or her to be. When patients' family members actively participate in self-management education programs, their opinions may be influenced positively with regard to the patients' capacities. Of course, it will not always be possible to have spouses or other close relatives participate in patient education (for example, when patients are single). While patient education can lead to significant improvements, inclusion of family members may further enhance outcomes.

7. A proper evaluation of the program's effectiveness. The National Arthritis Advisory Board's standards for arthritis patient education demand that pa- 
tient education programs demonstrate their effectiveness in maintaining or improving health status $(1,2)$. Effects of educational programs on knowledge, behavior, and health status should be evaluated. In our view, the effectiveness of patient education should be evaluated using experimental designs with experimental and control groups and pre- and post-test measures. A control or comparison group is necessary because in many cases of arthritis, a slow deterioration can be expected (14). Therefore, maintaining the same level of disability or pain in an educated group of patients could be considered a success. In this case, comparing the pre-intervention status to the post-intervention status in the educated group might lead to the wrong conclusion that the educational intervention was not effective. Furthermore, it is not enough to assess only the short-term effects of a few weeks or months. It is very important to assess the long-term effects of educational interventions after 6 months or longer. Keefe and Van Horn (54) recently reviewed the long-term effects of cognitive-behavioral therapy, arthritis education interventions, and combined cognitive-behavioral therapy-arthritis education interventions for patients with RA. They concluded that although some RA patients can maintain improvements in pain and disability for longer periods, other RA patients cannot. In the evaluation of our educational group program for RA patients, we also found that after 14 months, many positive effects had disappeared, although we still found positive effects on knowledge, self-efficacy, and the practice of physical exercise (9).

\section{Conclusions}

The effectiveness of arthritis patient education depends heavily on the quality of planning. That means a careful analysis of the problem, the behaviors involved, and the determinants of the behavior. Based on this analysis, an educational intervention can be developed. We reviewed an approach based on the selfefficacy paradigm and principles derived from it. These principles can serve as a basis for planning and evaluating arthritis patient education programs. In patient education practice, however, it is not always possible or necessary to meet all the criteria. This does not mean that a program is less valuable. The necessity of meeting some of the criteria is dependent on the findings of a thorough problem analysis, the objectives of the patient education, and the available resources (personnel, financial support). However, the model of patient education and the criteria we have presented can be a useful tool in evaluating and adjusting existing programs or in developing new programs.

\section{REFERENCES}

1. Burckhardt CS: Arthritis and musculoskeletal patient education standards. Arthritis Care Res 7:1-4, 1994

2. Lorig K, Visser A: Arthritis patient education standards: a model for the future. Patient Educ Couns 24:3-7, 1994

3. Green LW, Kreuter MW: Health Promotion Planning: An Educational and Environmental Approach. Mountain View, CA, Mayfield, 1991

4. Kok G: Quality of planning as a decisive determinant of health education effectiveness. Int J Health Educ 11: $5-8,1992$

5. Daltroy LH, Liang MH: Arthritis education: opportunities and state of the art. Health Educ Q 20:3-16, 1993

6. Hirano PC, Laurent DD, Lorig K: Arthritis patient education studies, 1987-1991: a review of the literature. Patient Educ Couns 24:9-54, 1994

7. Kirwan JR: Patient education in rheumatology. Curr Opin Rheumatol 2:336-339, 1990

8. Lorig K, Konkol L, Gonzalez V: Arthritis patient education: a review of the literature. Patient Educ Couns 10:207-252, 1987

9. Taal E, Riemsma RP, Brus HLM, Seydel ER, Rasker JJ, Wiegman O: Group education for patients with rheumatoid arthritis. Patient Educ Couns 20:177-187, 1993

10. DeVellis RF, Blalock SJ: Psychological and educational interventions to reduce arthritis disability. Baillieres Clin Rheumatol 7:397-416, 1993

11. McCracken LM: Cognitive-behavioral treatment of rheumatoid arthritis: a preliminary review of efficacy and methodology. Ann Behav Med 13:57-65, 1991

12. Holroyd KA, Creer TL, editors: Self-Management of Chronic Disease: Handbook of Clinical Interventions and Research. Athens, OH, Academic Press, 1986

13. Holman H, Lorig K: Perceived self-efficacy in self-management of chronic disease. In, Self-Efficacy: Thought Control of Action. Edited by R Schwarzer. Washington, DC, Hemisphere Publishing Corporation, 1992

14. Rasker JJ, Cosh JA: The natural history of rheumatoid arthritis over 20 years: clinical symptoms, radiological signs, treatment, mortality and prognostic significance of early features. Clin Rheumatol 6 (suppl 2):5-11, 1987

15. Scott DL, Symmons DPM, Coulton BL, Popert AJ: Longterm outcome of treating rheumatoid arthritis: results after 20 years. Lancet i:1108-1111, 1987

16. Ruddy S: The management of rheumatoid arthritis. In, Textbook of Rheumatology. Vol. 1. Edited by WN Kelley, ED Harris Jr, S Ruddy, CB Sledge. Philadelphia, WB Saunders, 1985

17. Bandura A: Social Foundations of Thought and Action: A Social Cognitive Theory. Englewood, NJ, PrenticeHall, 1986

18. Bandura A: Self-efficacy mechanism in psychobiologic functioning. In, Self-Efficacy: Thought Control of Action. Edited by R Schwarzer. Washington, DC, Hemisphere Publishing Corporation, 1992

19. Engel GL: The need for a new medical model: a challenge for biomedicine. Science 196:129-136, 1977 
20. Parker JC, Bradley LA, DeVellis RM, Gerber LH, Holman HR, Keefe FJ, Lawrence TS, Liang MH, Lorig KR, Nicassio PM, Revenson TA, Rogers MP, Wallston KA, Wilson MG, Wolfe F: Biopsychosocial contributions to the management of arthritis disability: blueprints from an NIDRR-sponsored conference. Arthritis Rheum 36:885889, 1993

21. Bandura A: Self-efficacy mechanism in physiological activation and health-promoting behavior. In, Neurobiology of Learning, Emotion and Affect. Edited by J Madden IV. New York, Raven, 1991

22. O'Leary A: Self-efficacy and health. Behav Res Ther 23: 437-451, 1985

23. Ewart CK, Taylor CB, Reese LB, DeBusk RF: Effects of early post-myocardial infarction exercise testing on selfperception and subsequent physical activity. Am J Cardiol 51:1076-1080, 1983

24. Schwarzer R: Self-Efficacy: Thought Control of Action. Washington, DC, Hemisphere Publishing Corporation, 1992

25. Seydel ER, Taal E, Wiegman O: Risk-appraisal, outcome and self-efficacy expectancies: cognitive factors in preventive behaviour related to cancer. Psychol Health 4: 99-109, 1990

26. Wiegman O, Taal E, VandenBogaard J, Gutteling JM: Protection motivation theory variables as predictors of behavioural intentions in three domains of risk management. In, Lifestyles, Stress and Health: New Developments in Health Psychology. Edited by JAM Winnubst, S Maes. Leiden, DSWO Press, 1992

27. Thoresen CE, Kirmil-Gray K: Self-management psychology and the treatment of childhood asthma. J Allergy Clin Immunol 72:596-606, 1983

28. Gonzalez VM, Goeppinger J, Lorig K: Four psychosocial theories and their application to patient education and clinical practice. Arthritis Care Res 3:132-143, 1990

29. Lorig K, Gonzalez V: The integration of theory with practice: a 12-year case study. Health Educ Q 19:355-368, 1992

30. Bandura A, Cervone D: Self-evaluative and self-efficacy mechanisms governing the motivational effects of goal systems. J Pers Soc Psychol 45:1017-1028, 1983

31. Festinger L: A theory of social comparison processes. Hum Relations 7:117-140, 1954

32. Bradley LA, Young LD, Anderson KO, McDaniel LK, Turner RA, Agudelo CA: Psychological approaches to the management of arthritis pain. Soc Sci Med 19:13531360,1984

33. Shoor SM, Holman HR: Development of an instrument to explore psychological mediators of outcome in chronic arthritis. Trans Assoc Am Physicians 97:325331,1984

34. Buescher KL, Johnston JA, Parker JC, Smarr KL, Buckelew SP, Anderson SK, Walker SE: Relationship of selfefficacy to pain behavior. J Rheumatol 18:968-972, 1991

35. Lorig K, Lubeck D, Kraines RG, Seleznick M, Holman HR: Outcomes of self-help education for patients with arthritis. Arthritis Rheum 28:680-685, 1985
36. Lorig K, Seleznick M, Lubeck D, Ung E, Chastain RL, Holman HR: The beneficial outcomes of the arthritis self-management course are not adequately explained by behavior change. Arthritis Rheum 32:91-95, 1989

37. O'Leary A, Shoor S, Lorig K, Holman HR: A cognitive behavioral treatment for rheumatoid arthritis. Health Psychol 7:527-544, 1988

38. Taal E, Rasker JJ, Seydel ER, Wiegman O: Health status, adherence with health recommendations, self-efficacy and social support in patients with rheumatoid arthritis. Patient Educ Couns 20:63-76, 1993

39. Lorig K, Chastain RL, Ung E, Shoor S, Holman HR: Development and evaluation of a scale to measure perceived self-efficacy in people with arthritis. Arthritis Rheum 32:37-44, 1989

40. Lorig K, Holman $\mathrm{H}$ : Arthritis self-management studies: a twelve-year review. Health Educ Q 20:17-28, 1993

41. Turk DC, Meichenbaum DH: A cognitive-behavioural approach to pain management. In, Textbook of Pain. Second edition. Edited by PD Wall, R Melzack. Edinburgh, Churchill Livingstone, 1989

42. Manne SL, Zautra AJ: Coping with arthritis: current status and critique. Arthritis Rheum 35:1273-1280, 1992

43. Parker JC, Iverson GL, Smarr KL, Stucky-Ropp RC: Cognitive-behavioral approaches to pain management in rheumatoid arthritis. Arthritis Care Res 6:207-212, 1993

44. Parker JC, Frank RG, Beck NC, Smarr KL, Buescher KL, Phillips LR, Smith EI, Anderson SK, Walker SE: Pain management in rheumatoid arthritis patients: a cognitive-behavioral approach. Arthritis Rheum 31:593-601, 1988

45. Taylor CB, Bandura A, Ewart CK, Miller NH, DeBusk RF: Exercise testing to enhance wives' confidence in their husbands' capabilities soon after clinically uncomplicated acute myocardial infarction. Am I Cardiol 55: 635-638, 1985

46. Krol B, Sanderman R, Suurmeijer ThPBM: Social support, rheumatoid arthritis and quality of life: concepts, measurement and research. Patient Educ Couns 20:101120,1993

47. Lanza AF, Revenson TA: Social support interventions for rheumatoid arthritis patients: the cart before the horse? Health Educ Q 20:97-117, 1993

48. Manne SL, Zautra AJ: Spouse criticism and support: their association with coping and psychological adjustment among women with rheumatoid arthritis. J Pers Soc Psychol 56:608-617, 1989

49. Revenson TA, Schiaffino KM, Majerovitz SD, Gibofsky A: Social support as a double-edged sword: the relation of positive and problematic support to depression among rheumatoid arthritis patients. Soc Sci Med 33: 807-813, 1991

50. Radojevic V, Nicassio PN, Weisman MH: Behavioral intervention with and without family support for rheumatoid arthritis. Behav Ther 23:13-30, 1992

51. Taal E, Rasker JJ, Wiegman O, Brus HLM, Riemsma RP: Spouse participation in group self-management edu- 
cation for patients with rheumatoid arthritis (abstract). Scand J Rheumatol Suppl 97:24, 1994

52. Bartlett EE: Educational self-help approaches in childhood asthma. J Allergy Clin Immunol 72:545-554, 1983

53. Pieterse GC, Taal E, Seydel ER: Psychosociale Aspecten van Cara: Ziektelast en Interventiestrategieën voor $\mathrm{Pa}-$ tiëntenvoorlichting, Tweede Herziene Druk [Psychoso- cial Aspects of CARA: Health Status and Intervention Strategies for Patient Education. Second edition.] Enschede, Universiteit Twente, 1993

54. Keefe FJ, Van Horn Y: Cognitive-behavioral treatment of rheumatoid arthritis pain: maintaining treatment gains. Arthritis Care Res 6:213-222, 1993 